\title{
EN MEMORIA DE EUGENIO BULYGIN
}

MARTIN FARRELL ${ }^{a, b, c}$

mdfarrell@fibertel.com.ar

${ }^{A}$ Universidad de Buenos Aires, Argentina

${ }^{b}$ Universidad de Palermo, Buenos Aires, Argentina

${ }^{c}$ Instituto de Investigaciones Jurídicas y Sociales Dr. Ambrosio L. Gioja, Buenos Aires, Argentina

Cuando Ambrosio Gioja fue designado profesor titular del Filosofía del Derecho en la UBA, llegó al cargo acompañado de discípulos conocidos, entre los que se destacaba Genaro Carrió. La vocación docente de Gioja hizo que pronto se acercaran a él muchos jóvenes interesados en la materia, y entre ellos se destacaron ciertamente dos: Carlos Alchourrón y Eugenio Bulygin.

Ambos estudiaron, investigaron y enseñaron con Gioja, y ambos continuaron la obra de Gioja luego de su temprana muerte. Los dos se especializaron en lógica jurídica, y los dos lograron renombre internacional: Normative Systems sigue siendo un clásico de la materia. Ambos colaboraron, también juntos, en la comisión directiva de SADAF, y publicaron, también juntos, muchos otros trabajos de gran valor en filosofía del derecho.

Además de su tan destacada carrera como intelectual y docente, Eugenio Bulygin fue el primer decano de la Facultad de Derecho de la UBA luego del gobierno militar, y su tarea fue admirable. Él fue el arquitecto y ejecutor de la reforma del plan de estudios de la Facultad, con reformas pedagógicas que resultaron decisivas para la modernización y mejoramiento de la enseñanza del derecho.

$\mathrm{Al}$ concluir su decanato, Eugenio Bulygin fue designado juez de la Cámara de Apelaciones en lo Civil y Comercial Federal, cargo que desempeñó con distinción durante largos años.

Yo compartí con él su paso por la Facultad de Derecho, así como las tareas en la comisión directiva de SADAF y en la Cámara Federal. Nunca tuvimos una discrepancia en ninguno de los lugares en los estuvimos juntos: luchamos las mismas luchas y creímos los mismos credos.

Académicamente Eugenio Bulygin, como yo, permaneció fiel a las dos enseñanzas básicas de Gioja: el positivismo jurídico y el subjetivismo moral. Me dejó muchas lecciones en filosofía del derecho y en filosofía moral, participamos juntos de muchos buenos momentos, y me ofreció numerosas muestras de su amistad. 
No tengo más remedio que concluir con un lugar común: lamento mucho su muerte y extraño mucho su presencia.

Recibido el 18 de octubre de 2021; aceptado el 20 de octubre de 2021. 